\title{
Outcomes of the patients of heart failure with reduced ejection fraction receiving inotropic support in initial 6 hours: Insights from Manipal Heart Failure Registry
}

\author{
Ajit Singh ${ }^{1}$, Sheetal Chauhan ${ }^{2}$, Ganesh Paramasivam ${ }^{1}$, Tom Devasia ${ }^{1 *}$, Yeshwanth Rao ${ }^{3}$, Prasad Narayana Shetty ${ }^{1}$, \\ Navaneeth Amin ${ }^{1}$, Deepak Uppunda ${ }^{1}$, Hashir Kareem ${ }^{1}$ \\ ${ }^{1}$ Department of Cardiology, Kasturba Medical College, Manipal Academy of Higher Education, Manipal, India. \\ ${ }^{2}$ Department of Pharmacology, Melaka Manipal Medical College, Manipal Academy of Higher Education, Manipal, India. \\ ${ }^{3}$ Department of Pharmacology and Ethics, Saint James School of Medicine, Anguilla.
}

\section{ARTICLE INFO \\ Received on: $13 / 05 / 2019$ \\ Accepted on: 21/06/2019 \\ Available online: 03/08/2019}

Key words:

Heart failure, inotropes,

mortality; myocardial

contractility, MHFR,

re-hospitalizations.

\begin{abstract}
Heart failure (HF) is responsible for 1.8 million admissions annually in India with an additional burden of mortality and re-hospitalizations. Positive inotropes with multiple mechanisms, such as dopamine and levosimendan, are being used for more than three decades to treat the patients of acute HF with reduced ejection fraction (HFrEF). This study compared the outcomes of the dopamine and the levosimendan up to 180 days. We have selected the patients from Manipal Heart Failure Registry who were diagnosed to have HFrEF (left ventricular EF less than 50\%) and were initiated on either dopamine or levosimendan in first 6 hours of hospitalization. The study included a total of 187 patients; among them, 120 patients were analyzed in the dopamine group, and 67 patients in the levosimendan group. Dopamine was initiated as intravenous infusion with the dose of 2.5 microgram/ $/ \mathrm{kilogram} / \mathrm{minute}(\mathrm{mcg} / \mathrm{kg} / \mathrm{minute})$ and up-titrated up to $10 \mathrm{mcg} / \mathrm{kg} /$ minute. Levosimendan was also administered intravenously with a dose of $0.1 \mathrm{mcg} /$ $\mathrm{kg} /$ minute and up-titrated up to $0.4 \mathrm{mcg} / \mathrm{kg} /$ minute. The primary outcomes include a composite of all-cause mortality and re-hospitalization at 30-days and 180-days follow-ups. The in-hospital mortality, 30-days mortality and 180-days mortality, and composite outcomes were noted higher in levosimendan treated patients even after matched demographic parameters (age and gender) and comparable comorbidities and risk factors, i.e., smoking, alcohol consumption, hypertension, diabetes mellitus, and atrial fibrillation. However, reduced EF, raised serum creatinine, procalcitonin, and $\mathrm{N}$-terminal pro b-type natriuretic peptide levels and high use of digoxin were noticed in levosimendan group during the initial period of index-hospitalization and these can be considered as confounding factors for future studies.
\end{abstract}

\section{INTRODUCTION}

About 38 million individuals are living with Heart failure (HF) worldwide. HF is responsible for 1.8 million admissions annually in India with a huge burden of mortality and re-hospitalizations (Braunwald, 2015). HF is a clinical array of alterations in the heart structure or/and function (diastolic or systolic) which declines the desired circulatory functions

\footnotetext{
${ }^{*}$ Corresponding Author

Tom Devasia, Department of Cardiology, Kasturba Medical College, Manipal Academy of Higher Education, Manipal, India.

E-mail: gt.cardiology@gmail.com
}

(Ponikowski et al., 2016). The hemodynamic models showed that the HF is a defect in cardiac contractility. The drugs named inotropes that alter the cardiac contractility have been considered as an attractive pharmaco-therapeutic target (Felker and O'connor, 2001). Positive inotropes are being used for more than three decades to treat the patients of acute HF with reduced ejection fraction (HFrEF) (Tariq and Aronow, 2015). Clinical presentation of acute HF includes the new onset or sudden deterioration of signs and symptoms which extends from worsening dyspnea to pulmonary edema or acute critical stage of cardiogenic shock. Beta-adrenergic agonists, calcium-sensitizer, and phosphodiesterase III inhibitors are three classes of inotropes currently trending in practice with distinct mechanisms (Bistola and Chioncel, 2017). Dopamine 
and levosimendan are two important inotropes that show mixed mechanisms being used in acute decompensated HF (ADHF) or refractory $\mathrm{HF}$ for immediate relief from symptoms. Dopamine causes vasodilation at low dose administration by stimulating $\beta$-receptors and alfa-receptors which independently enhance the cardiac output and improve symptoms. Levosimendan improves myocardial contractility and hemodynamics by sensitizing troponin $\mathrm{C}$ to calcium; it shows anti-ischemic and vasodilatory effects too (Guha et al., 2018). These drugs are associated with short-term recovery from symptoms but did not show any longterm survival benefits (Felker and O'connor, 2001). Data on the comparison of the outcomes related to both drugs in acute HFrEF patients are very limited and not demonstrated clearly. Hence, this study was designed to compare the composite outcomes, including mortality and re-hospitalizations up to 180 days from the index hospitalization.

\section{MATERIALS AND METHODS}

\section{Study design and site}

The Manipal Heart Failure Registry (MHFR) is a prospective registry that documents the routine medical care and pattern of therapeutic management and long-term HF-related outcomes, including mortality and re-hospitalizations. The study was conducted at a South Indian tertiary care hospital.

\section{Study population/inclusion}

The study included the patients admitted to intensive care settings of the hospital for HF management between January 2016 and December 2016. We have selected the patients from MHFR who were diagnosed to have HFrEF (left ventricular ejection fraction less than 50\%) and initiated on either dopamine or levosimendan in first 6 hours of hospitalization. The study divided them into two groups based on the inotropic support (dopamine or levosimendan) they received initially.

\section{Treatment details}

Dopamine or levosimendan was given initially to manage the patients with worsened symptoms at index-hospitalization. Dopamine was initiated as an intravenous (IV) infusion with a dose of $2.5 \mathrm{microgram} / \mathrm{kilogram} /$ minute $(\mathrm{mcg} / \mathrm{kg} / \mathrm{minute})$ and up-titrated up to $10 \mathrm{mcg} / \mathrm{kg} /$ minute. Levosimendan was also administered as an IV infusion with a dose of $0.1 \mathrm{mcg} / \mathrm{kg} /$ minute and up-titrated up to $0.4 \mathrm{mcg} / \mathrm{kg} / \mathrm{minute}$. Both the drugs were used for a minimum of 12 hours.

\section{Study outcomes}

The primary outcome studied was a composite of allcause mortality and re-hospitalization. We have documented in-hospital mortality, 30-days cumulative mortality, and 180days cumulative mortality along with re-hospitalizations within 180 days. Composite outcomes/events were including all-cause mortality and re-hospitalizations at 30-days and 180-days followups. Re-hospitalization or mortality, whichever appeared first was taken to calculate the duration of events during follow-ups. Composite events are not the exact sum of mortality and rehospitalizations.

\section{Parameters observed}

Socio-demographic details, including gender, age, and clinical characteristics, including etiology, details of cardiac and non-cardiac comorbid conditions were documented. New York Heart Association (NYHA), functional classes, signs, and symptoms at presentation, were recorded. Investigations, including biomarkers, ejection fraction by an echocardiogram (ECHO), and further lab tests to diagnose co-morbidities were documented. Duration of hospitalization and intensive care unit stay was computed to correlate the outcomes in both the groups. Details about inotropic drugs, i.e., types, dose, and duration of therapy along with other concurrent drugs were noted and analyzed. Inhospital and post-discharge events were also recorded up to 180 days after index-hospitalization.

\section{Ethical considerations}

The institutional ethical committee has approved the study with the ethical approval number MUEC/20/2015-16. Informed consent was signed by all eligible patients recruited for the study.

\section{Statistical analysis}

Means and the standard deviation were used to present continuous data. Proportions were calculated for categorical data. Categorical variables were compared using the Chi-square test, and continuous variables were compared through $t$-tests. Thirty daysmortality and 180-days mortality were estimated as cumulative proportions. Univariate survival analysis was performed to compare the prognosis between dopamine and levosimendan using Kaplan-Meier survival plots and log-rank test. Assumption of deviation from the proportional hazard was analyzed through log-minus-log plots. Statistical significance was considered at $p$ value less than 0.05. IBM SPSS Statistics version 20.0 (IBM Corp. Armonk, NY) was used for data entry and statistical analysis purpose.

\section{RESULTS}

\section{Socio-demographic and clinical characters}

We, therefore, included a total of 187 patients of $\mathrm{HFrEF}$ who received either dopamine or levosimendan during the mentioned period. Among the total, 120 patients were analyzed in the dopamine group and 67 patients in the levosimendan group. Socio-demographic parameters including age, gender, and social habits were assessed which were not different significantly $(p>$ $0.05)$ in both the groups. Ischemic heart disease was presented in $64 \%$ of patients in the dopamine group against $31.5 \%$ in the levosimendan group, and it was significantly high $(p<0.001)$.

Comorbid conditions, NYHA functional class, signs, and symptoms were noted at first presentation during index hospitalization (Table 1). Hypertension was presented in the highest proportion of patients $(46.5 \%)$ followed by diabetes mellitus (39.0\%) and atrial fibrillation (AF; 20.9\%), and distribution of comorbidities was not significantly different in both the study groups $(p>0.05)$. Use of ventilation (mechanical or non-invasive) and length of stay (LOS) in the hospital were assessed under health resources utilization (HRU), and there was no significant difference noted in the utilization of healthcare 
Table 1. Socio-demographic and clinical characters of the study population and comparison between dopamine and levosimendan groups.

\begin{tabular}{|c|c|c|c|c|}
\hline Variables & Total $[n, 187(\%)]$ & Dopamine Group [n, $120(\%)]$ & Levosimendan group $[n, 67(\%)]$ & $p$ value \\
\hline \multicolumn{5}{|l|}{ Socio-demographic details } \\
\hline Age, mean $\pm \mathrm{SD}$, median (years) & $64.6 \pm 13.7,67$ & $64.7 \pm 13.9,68$ & $64.5 \pm 13.6,65$ & 0.928 \\
\hline Male gender & $121(64.7)$ & $72(60.0)$ & $49(73.1)$ & 0.072 \\
\hline Smoking & $86(45.9)$ & $55(45.8)$ & $31(46.3)$ & 0.952 \\
\hline Alcohol & $97(51.9)$ & $61(50.8)$ & $36(53.7)$ & 0.092 \\
\hline Ischemic etiology & $98(52.4)$ & $77(64)$ & $21(31.5)$ & $<0.001$ \\
\hline \multicolumn{5}{|l|}{ Comorbidities } \\
\hline Hypertension & $87(46.5)$ & $55(45.8)$ & $32(47.7)$ & 0.429 \\
\hline Diabetes mellitus & $73(39.0)$ & $42(35.0)$ & $31(46.2)$ & 0.252 \\
\hline Atrial fibrillation & $39(20.9)$ & $23(19.2)$ & $16(23.9)$ & 0.399 \\
\hline Renal disease & $39(20.8)$ & $21(17.5)$ & $18(26.8)$ & 0.057 \\
\hline Thyroid dysfunction & $19(10.2)$ & $13(10.8)$ & $6(8.9)$ & 0.890 \\
\hline \multicolumn{5}{|c|}{ New York Heart Association functional class, sign and symptoms at index-hospitalization } \\
\hline NYHA III/IV & $144(77.0)$ & $93(77.5)$ & $51(76.4)$ & 0.067 \\
\hline Pulmonary rales & $152(81.3)$ & $96(80.0)$ & $56(83.6)$ & 0.742 \\
\hline Low urine output & $94(50.3)$ & $46(38.3)$ & $48(71.6)$ & 0.004 \\
\hline Congestion in chest X-ray & $126(67.4)$ & $67(59.8)$ & $59(88.1)$ & $<0.001$ \\
\hline \multicolumn{5}{|l|}{ Healthcare resources utilization } \\
\hline Ventilation (NIV/MV) & $89(47.6)$ & $102(85.0)$ & $53(79.1)$ & 0.128 \\
\hline Length of stay (days) & $6.4 \pm 4.8$ & $6.7 \pm 4.5$ & $5.8 \pm 5.3$ & 0.229 \\
\hline \multicolumn{5}{|c|}{ Investigations (Mean $\pm \mathrm{SD}$ and/or median if applicable) } \\
\hline Ejection fraction $(\%)$ & $36.3 \pm 9.3$ & $37.9 \pm 7.9$ & $33.4 \pm 7.7$ & $<0.001$ \\
\hline Systolic BP (mmHg) & $108.1 \pm 22.8$ & $101.5 \pm 16.8$ & $119.9 \pm 26.2$ & 0.093 \\
\hline Heart rate (per min.) & $89.7 \pm 19.1$ & $92.1 \pm 21.4$ & $84.1 \pm 10.3$ & 0.023 \\
\hline NT-proBNP (median) (pg/ml) & $9,154 \pm 8,283,4,702$ & $6,979.8 \pm 5,602,3,749$ & $13,140 \pm 11,748,8,455$ & $<0.001$ \\
\hline Hemoglobin (g/dl) & $12.2 \pm 2.2$ & $12.5 \pm 2.3$ & $11.8 \pm 2.1$ & 0.062 \\
\hline Total leucocyte count $\left(* 10^{3} / \mathrm{microL}\right)$ & $12.2 \pm 5.2$ & $12.5 \pm 5.2$ & $11.4 \pm .9$ & 0.163 \\
\hline Serum Creatinine (mg/dl) & $1.1 \pm 0.6$ & $0.9 \pm 0.5$ & $1.4 \pm 0.8$ & 0.032 \\
\hline Glycosylated hemoglobin (\%) & $6.7 \pm 1.7$ & $6.7 \pm 1.9$ & $6.7 \pm 1.2$ & 0.989 \\
\hline Albumin $(\mathrm{g} / \mathrm{dl})$ & $3.7 \pm 0.6$ & $3.8 \pm 0.6$ & $3.6 \pm 0.7$ & 0.048 \\
\hline Procalcitonin (ng/ml) & $2.5 \pm 1.3$ & $1.8 \pm 1.2$ & $3.7 \pm 2.1$ & 0.001 \\
\hline
\end{tabular}

$\mathrm{SD}=$ Standard deviation, NIV $=$ Non-invasive ventilation, $\mathrm{MV}=$ Mechanical ventilation, NT-proBNP $=$ N-terminal pro b-type natriuretic peptide.

resources between dopamine and levosimendan group $(\mathrm{P}, 0.128$ and 0.229 respectively). Details of the investigations done during the index-hospitalization are given in Table 1. High N-terminal pro b-type natriuretic peptide (NT-proBNP) $(13,140 \pm 11,748 \mathrm{pg} /$ $\mathrm{ml} v s .6,979 \pm 5,602 \mathrm{pg} / \mathrm{ml} ; p<0.001)$ and serum creatinine $(1.4 \pm$ $0.8 \mathrm{mg} / \mathrm{dl} v s .0 .9 \pm 0.5 \mathrm{mg} / \mathrm{dl} ; p=0.032)$ levels and low EF (33.4 $\pm 7.7 \%$ vs. $37.7 \pm 7.9 \% ; p<0.001)$ were recorded during first 6 hours of the index-hospitalization in levosimendan group, all the parameters were significantly different from the patients who received dopamine.

\section{Concurrent medications}

The median duration of dopamine use was 19 hours (range 12-50 hours), whereas levosimendan was used for 23 hours (range 12-72 hours). Medications other than dopamine and levosimendan were used for symptoms relief and the management of the comorbidities. Evidence-based drugs, i.e., IV furosemide were administered in $93.3 \%$ and $92.5 \%$ patients in the dopamine group and levosimendan group, respectively with no significant difference. The dose of IV furosemide was significantly low in the dopamine group than the comparison (levosimendan) group ( $p$ value, 0.015). Disease-modifying drugs and guidelines directed medical therapy (GDMT), such as beta-blockers (BB), angiotensin-converting-enzyme inhibitor (ACE-Is), angiotensin II receptor blockers (ARBs), and aldosterone antagonists were given in similar proportions in both the groups $(p>0.05)$. Drugs including antiplatelet agents, statins, amiodarone, oral hypoglycemic agents (OHAs), and insulin were used to manage comorbid conditions and details are presented in Table 2. Digoxin was used in a very high proportion in addition to levosimendan than dopamine $(61.2 \%$ vs. $10.8 \% ; p<0.001)$.

\section{Outcomes}

Composite outcomes and cumulative mortality for 180days follow-up period were calculated for all the patients and between both the study groups. There was a significant difference 
noted in all types of outcomes except re-hospitalizations alone, between dopamine group and levosimendan group (Table 3).

\section{Prognosis comparison}

Survival analysis using Kaplan-Meier curve was performed for in-hospital mortality, 30-days composite outcomes, 180-days cumulative mortality, and 180-days composite outcomes between dopamine and levosimendan groups. Patients in the dopamine group showed significantly prolonged survival than the levosimendan group in all outcome parameters by log-rank testing (Fig. 1).

\section{DISCUSSION}

Acute HF patients appear critical due to several other conditions, such as ischemia, left ventricular dysfunction, inflammatory activation, and arrhythmias. Blood pressure (BP) and heart rate (HR) control and management of acute coronary syndromes and arrhythmias in HF patients are the primary goals (Huang et al., 2013). When HF is acute and severe and not responding to first-line drugs, inotropes are usually given to stabilize the hemodynamics (Bayram et al., 2005). Outcomes were compared for 180 days between dopamine and levosimendan in acute HF patients with reduced ejection fraction. The study showed better outcomes and survival in the dopamine group while considering equally distributed baseline characteristics, i.e., socio-demographic parameters, comorbidities, NYHA functional class at presentation and HRU and concurrent drugs with no significant difference except for digoxin. High NT-proBNP, serum creatinine, procalcitonin levels, and low EF, and ischemic etiology in levosimendan group and use of digoxin in addition to levosimendan in initial period of hospitalization were noticed as confounding factors or the factors influencing the poor outcomes in levosimendan group in comparison to dopamine group.

Inotropes are not included in GDMT or evidencebased therapy for heart failure treatment, but they are being used worldwide despite the sobering results of clinical trials. This is may be due to limited therapeutic options for the sub-groups of advanced HF where BB, ACE-Is, or diuretics fails to improve symptoms or the patients need inotropes as additional support (Felker and O'connor, 2001). Long-term inotropic therapy is not recommended as long-term outcomes are not in favor, but it can be used for long-term as a bridging therapy in the patients waiting for definitive treatment (Upadya et al., 2004). Achieving adequate diuresis, regressing the symptoms of congestion, limiting the frequent hospitalizations, as well as LOS, are other appropriate goals of therapy in acute HF patients.

The current study presents the significant difference in EF between both the groups, which showed that the patients in levosimendan group were having severe left ventricle dysfunction as compared to the dopamine group which may have an impact on the long-term outcomes. An almost similar distribution of functional class in both groups gives additional strengths to the results. The high proportion of low-urine output and significantly high serum creatinine in patients who received levosimendan showed the choice of levosimendan over dopamine in renal injury patients. Use of dopamine is always controversial due to its dose-dependent adverse renal effect. Low-dose dopamine (LDD) ( $<3 \mathrm{mcg} / \mathrm{kg} / \mathrm{minute})$ shows dopaminergic effect by activating dopaminergic receptors resulting in vasodilation of coronary and renal arteries. Intermediate dose (3 to $10 \mathrm{mcg} / \mathrm{kg} /$ minute) of dopamine increases the inotropy and HR by activating beta-adrenergic receptors, but high dose $(>10 \mathrm{mcg} / \mathrm{kg} /$ minute) acts on alfa-adrenergic receptors as an agonist and causes peripheral vasoconstriction (Francis et al., 2014). Initially, LDD was recognized as "renal dose" but it remained controversial after Renal Optimization Strategies Evaluation in Acute Heart Failure (ROSE AHF) trial. ROSE AHF concluded that the LDD was not beneficial for renal care in acute HF patients (Chen et al., 2013). A meta-analysis concluded that the LDD decreases the serum creatinine levels and promotes diuresis in HF patients. LDD enhances the estimated glomerular filtration rate (Xing et al., 2016). The Dopamine in Acute Decompensated Heart Failure II (DAD-HF II) randomized trial studied 161 patients ADHF in three different groups of high-dose furosemide, low-dose furosemide with LDD and low-dose diuretics. LDD showed no benefits in short-term and long-term mortality and other secondary outcomes (Triposkiadis et al., 2014). In the present study the low-dose of furosemide was used with low or intermediate

Table 2. Concurrent medications during index-hospitalization.

\begin{tabular}{lcccc}
\hline Drugs & Total $[\boldsymbol{n}, \mathbf{1 8 7}(\mathbf{\%})]$ & Dopamine group [n, 120 (\%)] & Levosimendan group & $\boldsymbol{p}$ value \\
\hline IV furosemide & $174(94.1)$ & $112(93.3)$ & $62(92.5)$ & 0.503 \\
Dose of furosemide (mean $\pm \mathrm{SD})$ & $39.7 \pm 20.1$ & $36.9 \pm 19.1$ & $46.1 \pm 21.1$ & 0.015 \\
Spironolactone & $62(33.2)$ & $38(31.7)$ & $24(35.8)$ & 0.192 \\
Isosorbide dinitrate/hydralazine & $92(49.4)$ & $63(52.5)$ & $29(43.2)$ & 0.159 \\
Antiplatelet drugs & $166(88.8)$ & $107(89.2)$ & $59(88.1)$ & 0.862 \\
Statin therapy & $163(87.2)$ & $106(88.3)$ & $57(85.1)$ & 0.258 \\
Beta blockers & $67(35.8)$ & $44(36.7)$ & $23(34.3)$ & 0.672 \\
CCBs & $34(18.2)$ & $21(17.1)$ & $13(19.4)$ & 0.512 \\
ARBs/ACE-Is & $97(51.9)$ & $66(55.0)$ & $32(47.8)$ & 0.232 \\
Amiodarone & $29(15.5)$ & $20(16.7)$ & $9(13.4)$ & 0.548 \\
Digoxin & $54(28.9)$ & $13(10.8)$ & $41(61.2)$ & $<0.001$ \\
OHAs & $49(26.2)$ & $31(25.8)$ & $18(26.9)$ & 0.638 \\
Insulin & $68(36.4)$ & $43(35.8)$ & $25(37.3)$ & 0.616 \\
\hline
\end{tabular}

$\mathrm{CCBs}=$ Calcium channel blocker, $\mathrm{ACE}-\mathrm{I}=$ Angiotensin-converting-enzyme inhibitor, $\mathrm{ARB}=$ Angiotensin II receptor blockers, $\mathrm{OHA}=$ Oral hypoglycemic agent 
dose $(<10 \mathrm{mcg} / \mathrm{kg} / \mathrm{minute})$ of dopamine and it showed the significantly better short-term and long-term outcomes. DAD-HF analyzed 60 patients showed that the LDD with low-dose furosemide did not show any improvement in renal injury in ADHF patients (Giamouzis et al., 2010). In the present study, renal parameters were not analyzed to compare the effect of LDD in HF patients with renal injury.
There is no head-to-head comparison available for the efficacy and long-term outcomes between dopamine and levosimendan where comparisons of dopamine with dobutamine and levosimendan with dobutamine are well studied. Dzhaiani et al. (2011) have compared the short-term efficacy of levosimendan and dopamine in 30 patients with resistant cardiac failure in Russia

Table 3. 180-days outcomes and prognosis in the study population.

\begin{tabular}{|c|c|c|c|c|}
\hline Outcomes & Total $[n, 187(\%)]$ & Dopamine group $[n, 120(\%)]$ & Levosimendan group $[n, 67(\%)]$ & $p$ value \\
\hline \multicolumn{5}{|l|}{ Mortality } \\
\hline In-hospital & $39(20.8)$ & $17(14.2)$ & $22(32.68)$ & 0.001 \\
\hline 30-days mortality & $46(24.6)$ & $21(17.5)$ & $25(37.3)$ & 0.001 \\
\hline 180-days & $60(32.1)$ & $30(25.0)$ & $30(44.7)$ & 0.002 \\
\hline \multicolumn{5}{|c|}{ Re-hospitalization within 180 -days } \\
\hline 1 or $>1$ & $27(31.6)$ & $15(26.7)$ & $12(40.3)$ & 0.315 \\
\hline \multicolumn{5}{|c|}{ Composite events (mortality and re-hospitalizations) } \\
\hline 30-days & $61(32.6)$ & $29(24.2)$ & $32(47.8)$ & $<0.001$ \\
\hline 180-days & $84(44.4)$ & $43(35.8)$ & $41(59.7)$ & $<0.001$ \\
\hline
\end{tabular}
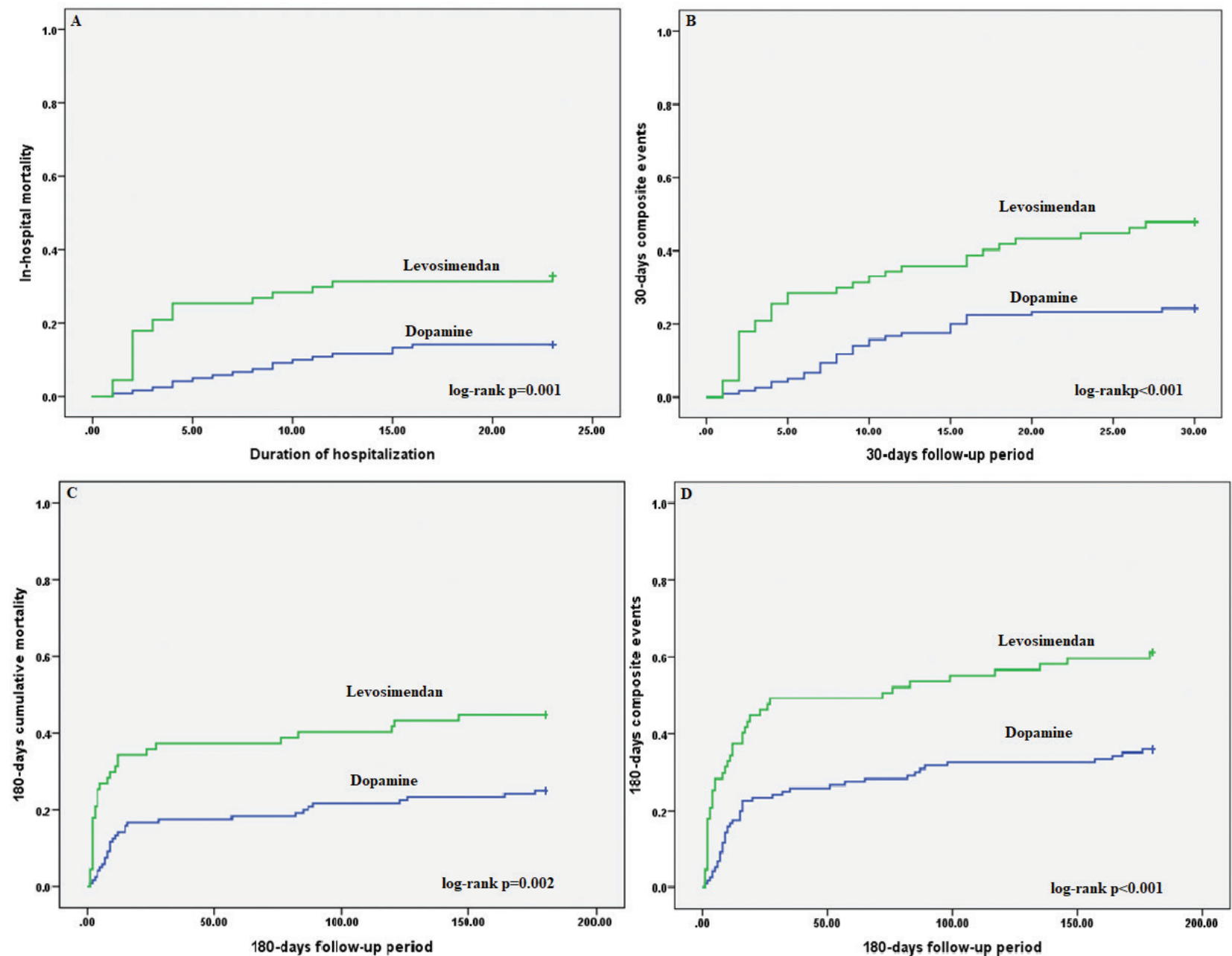

Figure 1. Mortality and composite outcomes/events at various follow-ups in dopamine and levosimendan groups. Kaplan-Meier mortality/composite events curves based on inotropic treatment in initial 6-hours at index-hospitalization. (A) Initial inotropic therapy and in-hospital mortality; (B) initial inotropic therapy and 30-days composite events; (C) initial inotropic therapy and 180-days cumulative mortality; and (D) initial inotropic therapy and 180-days composite events. 
and concluded that the levosimendan shows better prognosis than dopamine by producing earlier regress of symptoms and increased cardiac contractility.

Levosimendan is being used in several indications including severe LV dysfunction patients all around the globe except United States (De Luca et al., 2006; Gustafsson et al., 2017; Tavares et al., 2018). Levosimendan is used in 1/3 of the study population and not shown any positive results, and supported by various studies (Mathieu and Craig, 2011). Survival of Patients with Acute Heart Failure in Need of Intravenous Inotropic Support (SURVIVE) a randomized controlled trial comparing levosimendan with dobutamine involving 1,327 patients concluded that the levosimendan did not reduce the 180-days allcause mortality. Despite decreasing NT-proBNP levosimendan did not affect any secondary outcomes including re-hospitalizations (Mebazaa et al., 2007). Randomised Evaluations of Intravenous Levosimendan Efficacy (REVIVE II) also did not show the satisfactory benefits in long-term outcomes although the study was conducted to describe short-term outcomes of levosimendan (Packer et al., 2013). A meta-analysis comparing levosimendan and dobutamine in critically ill acute HF patients concluded that the levosimendan shows significant better improvements in the patients undergoing cardiac-surgery, receiving BB therapy and/or presented with ischemic etiology (Huang et al., 2013). A Greek study supported the prolonged infusion of levosimendan and its association with improved neuro-hormonal and clinical response (Aidonidis et al., 2011) and it also showed improved myocardial contractility in percutaneous coronary intervention-treated STelevation myocardial infarction patients who developed acute HF (Husebye et al., 2013). The recent randomized trials LIONHEART (Intermittent Intravenous Levosimendan in Ambulatory Advanced Chronic Heart Failure Patients) and LevoRep (Pulsed Infusions of Levosimendan in Outpatients with Advanced Heart Failure) showed the mixed opinion about levosimendan efficacy and safety in acute HF patients (Altenberger et al., 2014; ComínColet et al., 2018)

This is purely an observational study comparing the long-term outcomes between the patients receiving levosimendan or dopamine in initial 6 hours of hospitalizations, which showed lower in-hospital mortality, improved outcomes at 30 days and 180 days in dopamine group. Some more randomized head-to-head clinical trials are recommended to understand the mechanism and to confirm the results of this observational study. Further studies can be performed keeping the baseline EF similar for the study groups.

\section{CONCLUSION}

In patients who are age and gender-matched with comparable comorbidities and risk factors, i.e., smoking, alcohol consumption, hypertension, diabetes mellitus, and $\mathrm{AF}$, levosimendan group had higher in-hospital mortality, 30-days mortality and 180-days mortality, and composite outcomes. However, the levosimendan group also had reduced ejection fraction, raised serum creatinine, procalcitonin, and NT-proBNP levels and very high use of digoxin in initial period of indexhospitalization and these can be considered as confounding factors for future studies.

\section{ACKNOWLEDGMENT}

The authors would like to thank Ms. Husena Vadnagarwala for her support in manuscript preparation.

\section{AUTHOR'S CONTRIBUTION}

All mentioned authors are eligible to be an author as per the international committee of medical journal editors (ICMJE) requirements/guidelines.

\section{CONFLICT OF INTEREST}

Dr. Tom Devasia has received the research grants from Novartis Pharma, India, but this has no impact on Manipal Heart Failure Registry. Dr. Ajit Singh and Dr. Ganesh Paramasivam are working as co-investigator in a clinical trial funded by Novartis Pharma, India but it does not affect the current study. Dr. Prasad N Shetty also works for Novartis funded clinical trial as subinvestigator, but it does not relate to current study. Other authors do not declare any conflict of interests.

\section{FINANCIAL SUPPORT}

Manipal Academy of Higher Education supports MHFR by means of facilities needed to conduct the study. No external/ industry funds were received for the current study.

\section{REFERENCES}

Aidonidis G, Kanonidis I, Koutsimanis V, Neumann T, Erbel R, Sakadamis G. Efficiency and Safety of Prolonged Levosimendan Infusion in Patients with Acute Heart Failure. Cardiol Res Pract. 2011;2011:1-6.

Altenberger J, Parissis JT, Costard-Jaeckle A, Winter A, Ebner C, Karavidas A, Sihorsch K, Avgeropoulou E, Weber T, Dimopoulos L, Ulmer H, Poelzl G. Efficacy and safety of the pulsed infusions of levosimendan in outpatients with advanced heart failure (LevoRep) study: a multicentre randomized trial. Eur J Heart Fail, 2014; 16(8):898-906.

Bayram M, De Luca L, Massie MB, Gheorghiade M. Reassessment of dobutamine, dopamine, and milrinone in the management of acute heart failure syndromes. Am J Cardiol, 2005; 96(6):47-58.

Bistola V, Chioncel O. Inotropes in acute heart failure. Contin Cardiol Educ, 2017; 3(3):107-16.

Braunwald E. The war against heart failure: the Lancet lecture. Lancet, 2015; 385(9970):812-24.

Chen HH, Anstrom KJ, Givertz MM, Stevenson LW, Semigran MJ, Goldsmith SR, Bart BA, Bull DA, Stehlik J, LeWinter MM, Konstam MA, Huggins GS, Rouleau JL, O'Meara E, Tang WH, Starling RC, Butler J, Deswal A, Felker GM, O'Connor CM, Bonita RE, Margulies KB, Cappola TP, Ofili EO, Mann DL, Dávila-Román VG, McNulty SE, Borlaug BA, Velazquez EJ, Lee KL, Shah MR, Hernandez AF, Braunwald E, Redfield MM; NHLBI Heart Failure Clinical Research Network. Low-dose dopamine or low-dose nesiritide in acute heart failure with renal dysfunction: the ROSE acute heart failure randomized trial. JAMA, 2013; 310(23):2533-43.

Comín-Colet J, Manito N, Segovia-Cubero J, Delgado J, García Pinilla JM, Almenar L, Crespo-Leiro MG, Sionis A, Blasco T, Pascual-Figal D, Gonzalez-Vilchez F, Lambert-Rodríguez JL, Grau M, Bruguera J; LIONHEART Study Investigators. Efficacy and safety of intermittent intravenous outpatient administration of levosimendan in patients with advanced heart failure: the LION-HEART multicentre randomised trial. Eur J Heart Fail, 2018; 20(7):1128-36.

De Luca L, Colucci WS, Nieminen MS, Massie BM, Gheorghiade M. Evidence-based use of levosimendan in different clinical settings. Eur Heart J, 2006; 27(16):1908-20.

Dzhaiani NA, Kositsyna IV, Gnidkina NA, Tereshchenko SN Efficacy of levosimendan vs dopamine in patients with resistant cardiac failure. Terapevt Arkh, 2011; 83(6):53-9. 
Felker GM, O'connor CM. Inotropic therapy for heart failure: an evidence-based approach. Am Heart J, 2001; 142(3):393-401.

Francis GS, Bartos JA, Adatya S. Inotropes. J Am Coll Cardiol, 2014; 63(20):2069-78

Giamouzis G, Butler J, Starling RC, Karayannis G, Nastas J, Parisis C, Rovithis D, Economou D, Savvatis K, Kirlidis T, Tsaknakis T, Skoularigis J, Westermann D, Tschöpe C, Triposkiadis F. Impact of dopamine infusion on renal function in hospitalized heart failure patients: results of the Dopamine in Acute Decompensated Heart Failure (DAD-HF) Trial. J Card Fail, 2010; 16(12):922-30.

Guha S, Harikrishnan S, Ray S, Sethi R, Ramakrishnan S, Banerjee S, Bahl VK, Goswami KC, Banerjee AK, Shanmugasundaram S, Kerkar PG, Seth S, Yadav R, Kapoor A, Mahajan AU, Mohanan PP, Mishra S, Deb PK, Narasimhan C, Pancholia AK, Sinha A, Pradhan A, Alagesan R, Roy A, Vora A, Saxena A, Dasbiswas A, Srinivas BC, Chattopadhyay BP, Singh BP, Balachandar J, Balakrishnan KR, Pinto B, Manjunath CN, Lanjewar CP, Jain D, Sarma D, Paul GJ, Zachariah GA, Chopra HK, Vijayalakshmi IB, Tharakan JA, Dalal JJ, Sawhney JPS, Saha J, Christopher J, Talwar KK, Chandra KS, Venugopal K, Ganguly K, Hiremath MS, Hot M, Das MK, Bardolui N, Deshpande NV, Yadava OP, Bhardwaj P, Vishwakarma P, Rajput RK, Gupta R, Somasundaram S, Routray SN, Iyengar SS, Sanjay G, Tewari S, G S, Kumar S, Mookerjee S, Nair T, Mishra T, Samal UC, Kaul U, Chopra VK, Narain VS, Raj V, Lokhandwala Y. CSI position statement on management of heart failure in India. Indian Heart J, 2018; 70:S1-72.

Gustafsson F, Guarracino F, Schwinger RH. The inodilator levosimendan as a treatment for acute heart failure in various settings. Eur Heart J Suppl, 2017; 19(suppl_C):C2-7.

Huang X, Lei S, Zhu MF, Jiang RL, Huang LQ, Xia GL, Zhi YH. Levosimendan versus dobutamine in critically ill patients: a meta-analysis of randomized controlled trials. J Zhejiang Univ Sci B, 2013; 14(5):400-15.

Husebye T, Eritsland J, Müller C, Sandvik L, Arnesen H, Seljeflot I, Mangschau A, Bjørnerheim R, Andersen GØ. Levosimendan in acute heart failure following primary percutaneous coronary interventiontreated acute ST-elevation myocardial infarction. Results from the LEAF trial: a randomized, placebo-controlled study. Eur J Heart Fail, 2013; 15(5):565-72.

Mathieu S, Craig G. Levosimendan in the treatment of acute heart failure, cardiogenic and septic shock: a critical review. J Crit Care Med, 2011; 12(1):15-24.

Mebazaa A, Nieminen MS, Packer M, Cohen-Solal A, Kleber FX, Pocock SJ, Survive Investigators. Levosimendan vs dobutamine for patients with acute decompensated heart failure: the SURVIVE Randomized Trial. JAMA, 2007; 297(17):1883-91.

Packer M, Colucci W, Fisher L, Massie BM, Teerlink JR, Young J, Padley RJ, Thakkar R, Delgado-Herrera L, Salon J, Garratt C, Huang B,
Sarapohja T; REVIVE Heart Failure Study Group. Effect of levosimendan on the short-term clinical course of patients with acutely decompensated heart failure. JACC Heart Fail, 2013; 1(2):103-11.

Ponikowski P, Voors AA, Anker SD, Bueno H, Cleland JG, Coats AJ, Falk V, González-Juanatey JR, Harjola VP, Jankowska EA, Jessup M, Linde C, Nihoyannopoulos P, Parissis JT, Pieske B, Riley JP, Rosano GMC, Ruilope LM, Ruschitzka F, Rutten FH, van der Meer P; ESC Scientific Document Group. 2016 ESC Guidelines for the diagnosis and treatment of acute and chronic heart failure: the Task Force for the diagnosis and treatment of acute and chronic heart failure of the European Society of Cardiology (ESC). Developed with the special contribution of the Heart Failure Association (HFA) of the ESC. Eur J Heart Fail, 2016; 18(8):891-975.

Tariq S, Aronow W. Use of inotropic agents in treatment of systolic heart failure. Int J Mol Sci, 2015; 16(12):29060-8.

Tavares M, Andrade AC, Mebazaa A. Levosimendan use in several scenarios of acute heart failure. Arq Bras Cardiol, 2008; 90(3):231-5.

Triposkiadis FK, Butler J, Karayannis G, Starling RC, Filippatos G, Wolski K, Parissis J, Parisis C, Rovithis D, Koutrakis K, Skoularigis J, Antoniou CK, Chrysohoou C, Pitsavos C, Stefanadis C, Nastas J, Tsaknakis T, Mantziari L, Giannakoulas G, Karvounis H, Kalogeropoulos AP, Giamouzis G. Efficacy and safety of high dose versus low dose furosemide with or without dopamine infusion: the Dopamine in Acute Decompensated Heart Failure II (DAD-HF II) trial. Int J Cardiol, 2014; 172(1):115-21.

Upadya S, Lee FA, Saldarriaga C, Verma S, Sedrakyan A, Nystrom K, Katz SD. Home continuous positive inotropic infusion as a bridge to cardiac transplantation in patients with end-stage heart failure. $\mathrm{J}$ Heart Lung Transplant, 2004; 23(4):466-72.

Xing F, Hu X, Jiang J, Ma Y, Tang A. A meta-analysis of lowdose dopamine in heart failure. Int J Cardiol, 2016; 222:1003-11.

How to cite this article:

Singh A, Chauhan S, Paramasivam G, Devasia T, Rao Y, Shetty PR, Amin N, Uppunda D, Kareem H. Outcomes of the patients of heart failure with reduced ejection fraction receiving inotropic support in initial 6 hours: Insights from Manipal Heart Failure Registry. J Appl Pharm Sci, 2019; 9(08):011-017. 